\title{
Health Benefits and Application of Prebiotics in Foods
}

\section{Younis $\mathrm{K}^{1}$, Ahmad $\mathrm{S}^{1 *}$ and Jahan $\mathrm{K}^{2}$}

${ }^{1}$ Department of Post Harvest Engineering and Technology, Aligarh Muslim University, UP, India

${ }^{2}$ Department of Food Science and Technology GJUS\&T, Hisar, Haryana, India

\begin{abstract}
Prebiotics are supplements or foods that contain nondigestible food ingredients that selectively stimulate the favourable growth and/or enhance the activities of indigenous probiotic bacteria. Prebiotic therapies have been found to cure gut related diseases such as constipation relief, suppression of diarrhoea, reduction of the risks of osteoporosis, atherosclerotic cardiovascular disease associated with dyslipidemia, insulin resistance, obesity, and possibly type 2 diabetes. Fast life style of humans has changed the regular diets which were sufficiently enriched with fibers needed for proper gut work. Prebiotics are special fibers having selective fermenting ingredients that are needed by microbiota of human gut. Human colon is one of the body's most metabolically active organs because of the presence of microbiota. Lot of work has been done to overcome the problems related to the market foods having low fibre. Thus, this review will focus on the health benefits of prebiotics and their application in foods.
\end{abstract}

Keywords: Prebiotic; Probiotic; Microbiota; Nondigestible ingredients; Therapies

\section{Introduction}

The prebiotic word was first introduced by Gibson and Roberfroid in 1995 and is defined as "a non digestible food ingredient that beneficially affects the host by selectively stimulating the growth and/or activity of one or a limited number of bacteria in the colon, and thus improves host health" [1]. In common terms, bacterial species that are believed to be beneficial for health and well-being of humans use prebiotics as food. The fermentation features selecting a substance as prebiotic should include nutraceutical effects that extend beyond those of daily nutrition. The greater number of these effects have dealt with optimized colonic function and metabolism, such as increase in the expression or change in the composition of short-chain fatty acids, increased faecal weight, a mild decrease in luminal colon $\mathrm{pH}$, a decrease in nitrogenous end-products and reductive enzymes, an increased expression of the binding proteins or active carriers associated with mineral absorption, and immune system regulation [2,3]. On the basis of fermentability alone many substances and foods are being considered prebiotic $[4,5]$. Various whole foods are also being considered as prebiotics because of having different types of fibers, some of which are fermentable $[6,7]$. This information is confusing and lacks accurateness. Because foods consist of many different items with broad metabolic and nutritional effects, they should not be classified as narrowly as the prebiotic definition demands [8]. Besides, all macronutrients and their partially digested remnants reaching in the colon are able to be used as microbial substrate and produce a variety of fermentation products of a highly mixed nature, which may be either potentially beneficial or detrimental to health [9]. Consequently, the word prebiotic should be specific always: defined substances that exhibit a particular scientifically observed effect as stated by the prebiotic definition. Fermentable fibers in particular to other fibers are crucial for good health. But prebiotics are specified ingredients which are aimed to affect the specific bacteria, end- products of their fermentation, and possible health benefits on the host. So, prebiotics are typically oligosaccharides or more complex saccharides that are selectively used by commensal bacteria, including species considered to be beneficial for the human host. Prebiotics must resist host digestion, absorption, and adsorption before fermentation by one species of the resident microbiota [10]. The most common prebiotics are inulin, its derivatives fructooligosaccharides (FOSs) and galactooligosaccharides (GOSs), however, other complex saccharides and fibers have been recently considered as prebiotics. Poly- and oligosaccharides are commonly available in the usually taken diets [11]. They are mainly found in vegetables, as a reserve of energy to be used during germination. In the milk of other mammals some oligosaccharides with prebiotic activity are also found. The most commonly used prebiotics to develop the foodstuffs, including baby foods, are fructans (inulin and fructo-oligosaccharides, FOS) and galacto-oligosaccharides (GOS) [12,13]. They are believed as GRAS and their health-benefiting effects have been widely studied. For example, Inulin is a mixture of polymers composed of fructose units forming linear chains having variable degrees of polymerization, bound to a single glucose moiety. Chicory is the source of inulin which is isolated and purified from it after energy density [14]. On the other hand, various new prebiotics are having either natural origin (soy oligosaccharides, resistant starch, etc.) or synthetic origin (xylooligosaccharides, pyrodextrin, isomalte-oligosaccharides, lactosucrose, polydextrose, lactulose) are entering in the world market. In Japan many of these new products have been developed and some of them have been currently commercialized. However, these new compounds have been studied mainly in vitro and animal models. It is important to note that more clinical trials are needed to confirm their safety as well as their healthy effects in humans. It is becoming more and more acceptable that the specific health effects are due to specific bacterial strains, thanks to double blind placebo controlled clinical studies for providing an increasing number of citations [15]. It is now well-known that specific prebiotics encourage specific colon microbial populations both in vitro and in vivo [1]. For example, it has been found that amylomaize starch selectively stimulates the growth of (bifidobacteria) at the cost of (bacteroides and coliforms) [16]. Likewise, lactulose has been reported to support the growth of bifidobacteria and decrease the number of bacteroides in a continuous culture model [17] as well as in the human colon [18]. Additionally it has been found that the

*Corresonding author: Saghir Ahmad, Department of Post-Harvest Engineering and Technology, Aligarh Muslim University, UP, India, Tel: +91-9897114105; E-mail: alsaghirqadri@gmail.com

Received February 11, 2015; Accepted March 06, 2015; Published March 13 2015

Citation: Younis K, Ahmad S, Jahan K (2015) Health Benefits and Application of Prebiotics in Foods. J Food Process Technol 6: 433. doi: 10.4172/2157-7110.1000433

Copyright: ( 2015 Younis $\mathrm{K}$, et al. This is an open-access article distributed under the terms of the Creative Commons Attribution License, which permits unrestricted use, distribution, and reproduction in any medium, provided the original author and source are credited. 
faecal levels of $B$. lactis increases by oral administration of galactooligosaccharides [19]. On the contrary, b-glucans support the growth of lactobacilli more than the bifidobacteria [20]. So prebiotics support a specific microorganism for specific function.

\section{Functions}

Prebiotics reach the colon without being digested because of their chemical nature. A part of the material is not digested by pancreatic and small-bowel enzymes in the human gut and therefore, reaches the large bowel. The whole length of human gut is occupied by microorganisms with population numbers and species distribution characteristics of specific region of guts [21]. In the gut the relatively more stable colonies are in large intestines than smaller intestines because the transit time in small intestines is faster (4-6 h) than large intestines $(48-70 \mathrm{~h})$ in adults [22]. The $\mathrm{pH}$ and relatively low absorptive state of colon further supports large microbial colonisation and growth [23]. Due to this microflora, the colon has the ability to undertake complex hydrolytic digestive functions [24]. This involves breakdown of dietary components, complex carbohydrates and some proteins that are not hydrolysed or absorbed in the upper digestion tract. The colonic microflora derives their food from the undigested food e.g., nondigestible oligosaccharides, dietary fibre, and undigested protein. They also get their substrates from the mucin: the main glycoprotein constituent of the mucus. Therefore, any undigested food that reaches the colon e.g., nondigested carbohydrates, some peptides and proteins, certain lipids is a source of prebiotics [25]. Prebiotics have been suggested of having various health benefits on humans. It acts as a substrate for the useful gut microorganisms. The various benefits are:

\section{Gastroenteritis}

This is a common disease usually occurs due to ingestion of food or water contaminated with pathogenic microorganisms and/or their toxins. The main pathogenic organisms responsible for gastroenteritis are Shigellae, Salmonellae, Yersina enterocolitica, Campylobacter jejuni, Escherichia coli, Vibro cholera and Clostridus perfringens. These pathogens grow and colonise within the gastrointestinal tract and invade the host tissue or they secrete toxins in the foods before ingestion. These toxins disrupt the functions of the intestinal mucosa, causing nausea, vomiting and diarrhoea [26]. Therefore, prebiotics help to increase the population of useful organisms in large intestines that may possibly help in preventing gastroenteritis.

\section{Inflammatory bowel disease}

Inflammatory bowel disease has been related to the intestinal microbiota pathogenesis. One of the understandable ways for therapeutic intervention is probiotic treatment. Administration of prebiotics is an additional treatment $[27,28]$. Germinated barley foods are high in glutamine rich protein and hemicelluloses rich dietary fibre showing the prebiotic characteristics in the dextran sulfate sodium model of rat colitis as it has reduced the incidence of bloody diarrhoea and mucosal injury [29]. Germinated barley foods also displayed a greater ability to decrease the symptoms of dextran sulfate sodium colitis than that of a probiotic mixture of lactobacilli and $C$. butyricum [30]. A mixture of long chain inulin and oligosaccharide has shown the ability to decrease the inflammatory histological and gross cecal scores in the cecum and colon. It also decreased the levels of the pro-inflammatory cytokine IL- $1 \beta$ and increased the antiinflammatory TGF- $\beta$, at the same time it increases cecal lactobacillus and bifidobacterium levels [31]. Two other prebiotics lactulose and goat's milk oligosaccharides have shown an ability to reduce dextran sulfate sodium colitis in rats $[32,33]$. Despite having definitive proof on the therapeutic value of prebiotic in the treatment of inflammatory bowel disease from animal models. However, all prebiotics are not beneficial. As in the case of probiotics, not every prebiotics have anti-inflammatory effects in curing of inflammatory bowel disease, instead of that the severity of damage increases by some prebiotics. For example, fructooligosaccharides (FOS) has demonstrated antagonistic effects in the intestine. Administering of FOS as a dietary supplement ( $6 \% \mathrm{w} / \mathrm{w}$ of total diet), stimulate lactobacilli and bifidobacteria [34,35], and increase SCFAs in the large intestines [36] (a result that has been repeated in humans with ulcerative colitis $[37,38]$. Due to the rapid fermentation of elevated FOS levels in the cecum by cecal bacteria causing elevated levels of organic acids, which damage the mucosa of the cecum and colon [39]. Interestingly, however, oral gavage of FOS in the trinitrobenzene sulfonic acid (TNBS) rat model of colitis showed the decrease of severity of damage, which means by increasing lactic acid bacteria, lactate and butyrate causes to decrease inflammation scores and myeloperoxidase activity [40]. On the contrary, the effects of FOS in dextran sulfate sodium colitis showed that FOS treated rats had no shield from inflammation [41]. These contradictory conclusions may be due to differences in the model of colitis or may be a result of change in the delivery of FOS, leading to change the rates of fermentation, and consecutively SCFA production.

\section{Reduction of cancer risk}

Upon the administration of prebiotics it has been found that the activity of genotoxic enzyme decreases. A study carried on feeding galactooligosaccharides to humans showed decrease in nitroreductase (a mutagenic/carcinogenic substances) and also decreased levels of indole and isovaleric acid (produced due to proteolysis and deamination and markers of putrefaction) [42]. It has been shown that genotoxic enzymes b-glucosidase, b-glucuronidase, and arylsulphatase were strongly inhibited when galactooligosaccharides was applied on model system of the human gut [43]. As these effects happened quickly upon the addition of GOS to the system, changes attributable to population levels can be ruled out and it is more possible that direct inhibition by GOS or the production of repressors by bacteria was responsible. However, the proportion of bifidobacteria and lactobacilli increasing at the expense of bacteroides and clostridia may too decrease genotoxic enzyme production, as the former produces lower levels of such enzymes than the latter [44]. Further study was carried to see the effects of resistant starch administration to human flora-associated rats. Even though b-glucosidase increased while as b-glucuronidase and ammonia levels got decreased [45]. Another observation a high level of caecal butyrate important to the reduction of cancer is not only the major source of energy for colonocytes but also helps to maintain a healthy epithelium. It can also play an important role in preventing cancer [46]. These interactions include apoptosis induction, a process which is inactivated in cancer cells which would generally lead to their elimination and an increase in the immunogenicity of cancer cells due to an increase in cell surface proteins expression. However, the usual target bacteria for prebiotic use are bifidobacteria and lactobacilli but not butyrate producers. Therefore, other gut flora components (e.g. Eubacteria) should be fortified.

\section{Prevention and treatment of allergy}

The series of bacterial intestinal colonization is possibly important for the development of the immune response of neonates and young infants [47]. In pregnancy, the cell mediated immunity (T-helper 1 [Th1] type) is sidetracked away towards the humoral immunity (Th2 type) due to the cytokine inflammatory response profile of the fetus. Therefore, the general type of immune response in early 
babyhood is Th2. The lack or delay in the eventual shift of the main Th2 type of response to more of a balance between Th1 and Th2 type responses could well be the result of the risk of allergic disease [48]. In a review it was concluded that there was no firm conclusive evidence for giving prebiotics to prevent allergic disorders in infants [49]. However, a report showed that 132 infants were at risk of atopy because of parental atopy, based on the 2 year follow-up of randomized controlled trials. FOS and GOS or maltodextrin placebo were fed to infants with partially hydrolyzed formula in first 6 months of life. There was a reduced incidence of atopic disease in those which was given the prebiotic mixture of FOS and GOS. Increasing rates of atopic eczema, recurrent wheezing, and allergic urticaria were higher in the maltodextrin placebo group $(27.9 \%, 20.6 \%$, and $10.3 \%$, respectively) than in the intervention group $(13.6 \%, 7.6 \%$, and $1.5 \%)(\mathrm{P}=.05)$ [50]. After analyzed the relevant publications it was concluded that there is no sufficient proof currently available to support the use of probiotics, prebiotics, or synbiotics for the prevention or treatment of allergic dermatitis in children. Studies supporting the benefits of prebiotics, particularly for children fed formula either partially hydrolyzed or not partially hydrolyzed formula, which are previously being promoted to decrease the prevalence of atopic disease, are needed to continue till other recommendations can be made for the use of prebiotics in infants and toddlers to stop infection or atopic disease [51].

\section{Effects of prebiotics on bone mineralization}

Bone mass of an adult is dependent on supply as well as bioavailability of calcium. In either cases of deficiency osteoporosis is prone to occur and in addition to this it is highly associated with increasing age and postmenopausal conditions. Presently, osteoporosis treatment and prevention is restricted to increasing calcium uptake, or by stimulating bone formation. Even though, a lot of studies have been carried out on calcium metabolism using rats, results depicted that prebiotics play a role in escalating the bioavailability of calcium. But so far, only a few human trials have been translated from these results. Prebiotic consumption increasing calcium absorption has the majority supporting data from the rat studies where as human trials have had diverse results [52].

\section{Cardiovascular effects of prebiotics}

Obesity and diet have direct link with atherosclerosis, cardiovascular disease and type 2 diabetes [53,54], and there are number of animal experiments signifying the ability of prebiotics to influence the serum lipid levels [55,56]. Double-blind randomized controlled trials were carried on 12 humans using inulin, FOS and galacto-oligosaccharides (GOS) of the dosage of $15 \mathrm{~g}$ per day. It was shown that higher concentrations of faecal acetate in inulin and GOS treatment periods $(\mathrm{P}<0.05)$ lowered $\beta$-glucuronidase activity in inulin and GOS periods [57]. Alles et al. [58] investigates the effect of FOS (20 days) in diabetics on cholesterol and blood glucose using FOS 15 $\mathrm{g}$ per day. It was seen that there has been no changes in blood glucose. No effects on total, HDL, LDL cholesterol or serum triacylglycerol. A study on inulin supplement of $10 \mathrm{~g}$ per day was carried on 54 healthy middle aged volunteers using fasting blood samples to analyze lipids and glucose. It was seen that insulin concentrations got significantly lower in inulin group $(\mathrm{P}<0.01)$. Trends for lower triacylglycerol levels in inulin group $(\mathrm{P}<0.08)$ returned to baseline 4 weeks after end of study [59]. Similarly inulin supplement of $18 \mathrm{~g}$ per day for 6 weeks of human trails having hyperlipidaemic showed reduction in LDL as compare to those having normal diets [60]. A significant reduction in serum triglycerides was seen in hyperlipidaemic patients after 21 days administration of ice cream supplemented with inulin [61]. FOS in combination of inulin when used for 4 weeks on normal lipidaemic persons showed significant reduction in triacylglycerol [62].

\section{Food Applications of Prebiotics}

Both important technological characteristics and interesting nutritional properties have been shown by Prebiotics $[63,64]$. Some of them are found in fruits and vegetables and some can be processed industrially from renewable materials. In foods they affect considerably by improving organoleptic characteristics, enhancing both taste and mouth feel. As functional food ingredients prebiotics must be chemically stable to processing treatments of food, such as high temperature, low $\mathrm{pH}$, and Maillard reaction conditions. Therefore, if the prebiotic was degraded to its component mono- and disaccharides or chemically altered, a prebiotic would no longer provide selective stimulation of beneficial microorganisms and it was unavailable for bacterial metabolism [65]. A study ascertained the effect on the prebiotic activity by processing conditions of commercial prebiotics using a prebiotic activity assay. The results showed that a significant decrease in prebiotic activity was only seen when heating at low $\mathrm{pH}$, with one of the fructooligosaccharides (FOS) products being the least stable. Little change in activity was caused by other conditions [66-68]. These results help us in selecting of prebiotics as functional food ingredients and predicting the extent to which processing affects prebiotic activity. Presently known prebiotics and prebiotic candidates are nondigestible oligosaccharides. They are acquired either by extraction from plants (e.g., chicory inulin), enzymatic hydrolysis (e.g., oligofructose from inulin) or by synthesis (by trans-glycosylation reactions) from monoor disaccharides such as sucrose (fructooligosaccharides) or lactose (trans-galactosylated oligosaccharides or galactooligosaccharides) [69]. Among these prebiotics, inulin and oligosaccharides have been most studied prebiotics and recognized as dietary fibers in most countries [70]. Prebiotics can be used to offer a double benefit such as an improved organoleptic quality and a better-balanced nutritional composition [71]. As fiber ingredients the use of inulin and nondigestible oligosaccharides is simple and often leads to enhance taste and texture. Specific colonic bacteria, such as bifidobacteria and lactobacilli species readily ferment these particular forms of dietary fibre and by raising their cell population with the parallel production of short-chain fatty acids [72]. These acids, mainly butyrate, acetate, and propionate provide acidification of the bowel as well as metabolic energy for the host [73]. Lactose occurs wholly in the milk of mammals and one might observe from a teleological point of view that lactose ingestion provides specific health benefits beyond just being a source of energy to the suckling animal [74]. In fact, it is used in different foods such as in baby foods, cakes, biscuits, chocolates, sugar confectionary, and soups and sauces and the global demand has grown considerably over the previous 10 years to amount to approximately 500,000 t per annum [75]. Currently, more and more prebiotics are used in different foods as an ingredient which helps in the growth of health promoting colon microorganisms particularly probiotics and offer additional health benefits. Some of the recent works done in the development of prebiotic foods are as follows:

\section{Prebiotics in infant formula}

There are number of prebiotic substances present in human milk, the most abundant of which are oligosaccharides [76,77]. Many commercially available dietary food supplements are also added with oligosaccharide prebiotics. Concerning to their addition to infant food, the European Commission's Scientific Committee on Food concluded in 2003 that the addition of oligosaccharides to infant formulas had no major worry and including the studied infantformulas (formulas adapted 
especially for 6- to 12 -month-old infants), up to a total concentration of $0.8 \mathrm{~g} / \mathrm{dL}$ in ready-to-feed formula products [78]. Few randomized controlled trials have been examined to see the effects of fortifying prebiotic oligosaccharides to infant foods $[79,80]$. A study showed the effect of the addition of oligosaccharides having a concentration of $1 \mathrm{~g} / \mathrm{dL}$ to newly born infant formula for 1 month having $90 \%$ of GOSs and $10 \%$ of FOSs. In the oligosaccharide supplemented group the faecal bifidobacteria counts increased significantly when compared with the nonsupplemented group and the counts of bifidobacteria reached the range of a breastfed reference group. In another study, it was shown that the infants fed with the same oligosaccharide fortified formula. These infants had higher bifidobacteria counts as well as lactobacilli in their faecal matter. A multicenter trial was conducted that examined the efficiency of the fortification of prebiotics to infant foods. They stated the good overall tolerance and no undesirable effects during the study period of 12 weeks [81]. Also a large multicenter trials have been evaluated by United States in 2004 on the safety of FOS supplemented infant formula. The study demonstrated the effect of FOS supplemented infant formula for 12 week study period and was seen that the infant growth was maintained without having any adverse effects [82]. In weaning infant food formulas the fortification of prebiotics to solid foods shows to have a bifidogenic effect, as revealed by the results of recently published randomized controlled trials [83]. Infant food formulas containing either GOS or FOS are now marketed in the United States. On the other hand more information, including data from randomized controlled trials, is required before the efficacy of adding prebiotics to infant food formulas can be determined.

\section{Prebiotics in cheese}

Dairy products are considered a potential vehicle for prebiotics and probiotics and are increasingly being used to produce synbiotic foods. A research conducted to evaluate the potential of prebiotic in novel petit-suisse cheeses using an in vitro fermentation model. Prebiotics candidate (inulin, oligofructose, honey) and probiotics (Lactobacillus acidophilus, Bifidobacterium lactis) were combined in five petit-suisse cheese formulations and were tested in vitro with human faecal slurry. It was seen that with addition of prebiotics to a probiotic cheese (made using starter + probiotics) fastest fermentation and high lactic acid production, promoting increased growth rates of bifidobacteria and lactobacilli, were achieved. Addition of probiotics as starter culture to control cheese also resulted in high lactic acid production. In vitro conditions, cheese made from the combination of different prebiotics and probiotics shows potential functional petit-suisse cheese [84]. An investigation conducted to see the influence of prebiotic compounds (FOS and inulin), probiotic bacteria (Lactobacillus casei-01, Bifidobacterium lactis B94) and ripening time (0-60 days) on the free fatty acid (FFA) profile of cheese, with special prominence on the conjugated linoleic acid (CLA) content. 109-1010 $\mathrm{cfu} \mathrm{g}^{-1}$ cheese were recorded in both probiotic and synbiotic cheeses after 60 days of ripening, in spite of harsh conditions of low $\mathrm{pH}$ values (4.1-5.1) and low moisture content $(<30 \%, w / w)$. It was observed that the increases in total FFA and CLA during the ripening period, particularly in synbiotic cheeses having FOS and inulin (50:50) inoculated with B. lactis B94. Addition of prebiotic compounds in probiotic cheese is advantageous so far as functional CLA compounds are concerned plus an enhanced nutritional quality [85].

\section{Prebiotics in fermented milk}

The physicochemical composition (day 1 of storage) and rheological (days 1, 7, 14 and 21) were evaluated for the microfiltered cow's milk samples fermented with and without inulin, at temperatures of $4.0 \pm 0.1^{\circ} \mathrm{C}$ and $6.0 \pm 0.1^{\circ} \mathrm{C}$. The total solid content of the prebiotic fermented milk increased with the addition of inulin, also increased its acidity. The Power Law and Mizhari and Berk models described the flow of the fermented milks as shear thinning and non-Newtonian fluid behaviour. The apparent viscosity of the product added with inulin increased with storage time. The prebiotic fermented milk showed greater thixotropy and the hysteresis got lowered with an increase in the temperature [86]. Debon et al. used permeate obtained from the best microfiltration process for the preparation of fermented milks, with and without of inulin $\left(5 \mathrm{~g} 100 \mathrm{~g} \mathrm{~g}^{-1}\right)$, stored at $5 \pm 1^{\circ} \mathrm{C}$ for 28 days. It has been seen that the storage period and addition of inulin increased the total solids and carbohydrate contents, the caloric value and the acidity but decreased the $\mathrm{pH}$. Lower syneresis index resulted with the addition of inulin in a fermented product also with greater firmness and cohesiveness. The inulin addition in a product resulted with a greater tendency toward a greenish coloration [87]. Cruz et al. evaluated the effect of addition on physicochemical, rheological and microbiological characteristics of non-flavoured yogurt. There was no influence on the $\mathrm{pH}$, proteolysis or the viability of Streptococcus thermophilus or Lactobacillus bulgaricus during 28 days of refrigerated storage with the addition of oligofructose. Yogurt added with oligofructose was characterized as a weak gel, showing thixotropic and pseudoplastic behaviour as per the rheological measurements. As per the survival analysis $25 \%$ of the consumers rejected the yogurt added with different levels of oligofructose, and the level of oligofructose that can be added to the yogurt was shown to be $2.58 \%$ wt. V-1 [88].

\section{Prebiotics in dairy fruit beverages}

Guergoletto et al. evaluated the survival of Lactobacillus casei (LC1) when adhered to dehydrated prebiotic fibers. After vacuum drying in oat bran with $9 \% \beta$-glucan and green banana flour, viability of LC- 1 was $79 \%$ and $76 \%$, respectively. Images revealed by scanning electron microscopy showed no morphological changes in the cells adhered to these fibers and the cell protectant trehalose addition had a positive and significant effect on the survival of LC-1. Greater viability of LC-1 has been seen when adhered to the oat bran $\left(7.1 \log \mathrm{CFU} \mathrm{g}^{-1}\right)$ than in the free form $\left(2.4 \log \mathrm{CFU} \mathrm{g} \mathrm{g}^{-1}\right)$. Sensory evaluation showed that the probiotic oat bran added to a dairy fruit beverage was well accepted by consumers [89].

\section{Prebiotics in cereals}

Several studies have publicized the prebiotic activity of cereal derived arabinoxylan oligosaccharides (AXOS). A study investigated the in situ AXOS production during bread making process. Firstly AXOS producing ability of different xylanases was compared in whole meal bread making. Different dosages of xylanase were used originating from Bacillus subtilis, Aspergillus niger and Hypocrea jecorina, and thermophilic xylanase from $H$. jecorina (HjXynA). Dosages which do not impair dough manageability, arabinoxylan fraction are solubilised and cleaved to the largest extent by HjXynA, resulting in an AXOS content of $2.1 \%$ on dry basis and an average degree of polymerisation of 9. Secondly the HjXynA effect on the AXOS levels in dietary fibre enriched breads was studied. Breads fortified with rye or wheat bran treated with HjXynA yielded high-quality breads with AXOS levels above $2.0 \%$ with an average degree of polymerization of 26 and 19, respectively [90]. Due to wide occurrence of celiac disease and wheat allergy has led to an increasing demand for gluten-free foods that present an appropriate sensory acceptance. A consumer test was performed with 65 celiac people. Additionally, 15 trained assessors were used in the sensory profiling by using quantitative descriptive analysis (QDA). By using QDA, the samples differed significantly with respect 
to all parameters, and partial least squares (PLS) regression was used to recognize the factors of liking of gluten-free breads. The results show that the softness, traditional bread aroma, sweetness and crumb color are the most desired sensory properties of such products which can be considered as drivers of liking of prebiotic gluten free breads [91]. In a clinical study partially hydrolysed guar gum (PHGG) and fructooligosaccharides (FOS) were incorporated in biscuit and was assessed in human volunteers. The study showed consumption of biscuits added with FOS and PHGG gave a significant increase in faecal bifidobacterial numbers $\left(\mathrm{P}=2.15 \times 10^{-5}\right)$. Bifidobacteria increased from $9.18 \log 10$ cells $/ \mathrm{g}$ faeces to $9.59 \log 10$ cells/g faeces after the experimental treatment. There was small change in the total numbers of bacteria, Bacteroides spp., Clostridium spp. or Lactobacillus-Enterococcus spp. present in faecal samples collected over the course of the trial. No changes were observed in bacterial populations on eating of the placebo biscuits [92].

\section{Prebiotics in salad dressing}

A study conducted by Mantzouridou et al. to develop a low-inoil salad dressing emulsion, based on oat flour, that has both health promoting effect as well as provides growth to probiotic Lactobacillus paracasei subsp. paracasei DC412 with the functional properties also e.g. emulsion stabilization and thickening ability. Probiotic viability, following emulsion storage and enzymatic treatment, was persistent in oat flour presence at the levels near to those found for inulin. The dressing emulsion was further investigated by applying response surface methodology and the optimum formulation ( $\mathrm{g} / 100 \mathrm{~g})$ was as: oil (20), xanthan (0.475) and oat flour (3.0); viable cell counts of emulsions reached levels as high as $108 \mathrm{cfu} / \mathrm{g}$ after the refrigerated storage period of 7.5 weeks and treatment with simulated gastric and intestinal juices. In addition to enhancing cell viability, appreciable improvement of the emulsion rheological properties and physical stability of salad dressing occur by oat flour incorporation [93].

\section{Prebiotic as thermoprotector}

Bifidobacterium bifidum viability to spray-drying and with storage time can be considerably improved by adding aguamiel as a thermoprotector prebiotic offering resistance to oxygen diffusion. $B$. bifidum harvested in the late log phase were mixed with three different protective colloids blends exhibiting relatively high, medium and low activation energies with or without aguamiel were spray dried at 130 , 140 and $155^{\circ} \mathrm{C}$, and stored at $4^{\circ} \mathrm{C}$ at a water activity of 0.32 . The blend exhibiting highest activation energy $\left(40.7 \mathrm{~kJ} \mathrm{~mol}^{-1}\right)$, with aguamiel, and dried at $140^{\circ} \mathrm{C}$ showed best viability when microencapsulating the microorganism. After 5 weeks storage time at $4^{\circ} \mathrm{C}$ the viability ranged from $1.26 \times 10^{8} \mathrm{cfu} \mathrm{g}^{-1}$ immediately after drying to $6.0 \times 10^{6} \mathrm{cfu}^{-1}[94]$.

\section{Prebiotics in edible coating}

The idea for encapsulating probiotic living cells by prebiotic edible films was investigated. In combination of gelatine based matrices and plasticizer glycerol, four soluble fibres (inulin, polydextrose, glucose oligosaccharides and wheat dextrin) were selected as prebiotic cocomponents for the immobilisation of L. Rhamnosus GG. Glucoseoligosaccharides and polydextrose considerably improved the viability of L. rhamnosus GG during air drying (by 300\% and 75\% respectively), whereas a 33 and $80 \%$ decrease in viable counts was seen for inulin and wheat dextrin. On the other hand it was seen that inulin was the most effective at controlling the sub-lethal effects on L. rhamnosus GG during storage. Yet in all cases the prebiotics supplementation of edible films increased the storage stability of L. Rhamnosus GG [95].

\section{Prebiotics in custard}

Rheological and sensory properties were studied for low-fat custards added with (7.5 g/100 g) of long-chain inulin (TEX) and short-chain inulin (CLR) combined in different proportions (25:75, 50:50, and 75:25). Low-fat samples added with inulin blends did not cope to fully imitate the rheological behaviour of full-fat custard. However, inulin blends in the ratio of 50:50 of TEX: CLR added to the low-fat samples perceived to have the same creaminess and thickness as the full-fat sample. When this blend was used in combined with carrageenan gave thicker, creamier custard, which was preferred over the full-fat custard [96]. A seven-day period of refrigerated storage was studied for the changes in rheological properties and microstructure of inulin-enriched custard desserts. The comparison in desserts prepared with $7.5 \%$ short-chain inulin (CLR), long-chain inulin (TEX), native inulin (IQ), and a mixture of short and long-chain inulin (MIX) were carried out. During the seven-day storage period of CLR samples the rheological changes and inulin aggregates formation were not observed. Conversely TEX, MIX and IQ samples formed inulin aggregates and as a result became more thixotropic, consistent and elastic. The order of the rate of the inulin aggregates formation and the percentage of volume occupied by them was TEX $>$ MIX $>$ IQ. Although for both skimmedmilk and whole-milk samples the same trend was observed and the effects of inulin type and storage time on rheology and microstructure were less prominent in the whole-milk samples [96].

\section{Conclusion}

Prebiotics have a noteworthy effect on human health and have greater potential for incorporation into a broader range of common foodstuffs as they have both technical as well as nutritional properties. They act as substrate for the growth of probiotic bacteria (bifidobacteria and lactic acid bacteria), thus enhance the gastrointestinal functions and immune system. Prebiotics also increase the absorption of calcium and magnesium, influence blood glucose levels and improve plasma lipids. To confirm the health benefits of prebiotics by incorporating in formulated foods a long term clinical trials are needed, hence a lot of work is yet to be done.

\section{References}

1. Gibson GR, Roberfroid MB (1995) Dietary modulation of the human colonic microbiota: introducing the concept of prebiotics. J Nutr 125: 1401-1412.

2. Bournet FR, Brouns F, Tashiro Y, Duvillier V (2002) Nutral aspects of shortchain fructooligosaccharides: Natural occurrence chemistry physiology and health implications. Digestive and liver disease 34: 111-120.

3. Forchielli ML, Walker WA (2005) The role of gut-associated lymphoid tissues and mucosal defence. British J Nutr 93: 41-48.

4. Blaut M (2002) Relationship of prebiotics and food to intestinal microflora European J Nutr 41: S11-S16.

5. Winter D (2006) Probiotic and prebiotic foods Baylor Health Care System.

6. Dixon S (2006) Prebiotics and probiotics: What are they and why should I eat them? University of Michigan Comprehensive Cancer Center, USA.

7. Charalampopoulos D, Wang R, Pandiella SS, Webb C (2002) Application of cereals and cereal components in functional foods: A review. International J of Food Microbiology 79: 131-141.

8. Slavin J (2003) Why whole grains are protective: Biological mechanisms Proceedings of Nutr. Society 62: 129-134.

9. Priebe MG, Vonk RJ, Sun X, He T, Harmsen HJM, et al. (2002) The physiology of colonic metabolism Possibilities for interventions with pre- and probiotics. European J Nutr 41: 2-10.

10. Gibson GR (2008) J. of Clinical Gastroenterology 42: 75-79.

11. Vijn I, Smeekens S (1999) Fructan: More than a reserve carbohydrate? Plant Physiology 120: 351-360.

12. Kolida S, Gibson GR (2007) Prebiotic capacity of inulin-type fructans. The J of Nutr 137: 2503-2506. 
Citation: Younis K, Ahmad S, Jahan K (2015) Health Benefits and Application of Prebiotics in Foods. J Food Process Technol 6: 433. doi: 10.4172/2157-7110.1000433

13. Fanaro S, Boehm G, Garssen J (2005) Galacto-oligosaccharides and longchain fructo-oligosaccharides as prebiotics in infant formulas: A review. Acta Paediatrica Supplement 94: 22-26.

14. Archer BJ, Johnson SK, Devereux HM, Baxter AL (2004) Effect of fat replacement by inulin or lupin-kernel fibre on sausage patty acceptability postmeal perceptions of satiety and food intake in men. The British J Nutr 91: 591599.

15. Marteau P, Shanahan F (2003) Basic aspects and pharmacology of probiotics: an overview of pharmacokinetics mechanisms of action and side-effects. Best Pract Res Clin Gastroenterol 17: 725-740.

16. Wang X, Brown IL, Khaled D, Mahoney MC, Evans AJ, et al. (2002) Manipulation of colonic bacteria and volatile fatty acid production by dietary high amylose maize (amylomaize) starch granules. J Appl Microbiol 93: 390-397.

17. Owen RW (1997) Faecal steroids and colorectal carcinogenesis. Scand $J$ Gastroenterol Suppl 32: 76-82.

18. Bouhnik Y, Attar A, Joly FA, Riottot M, Dyard F, et al. (2004) Lactulose ingestion increases faecal bifidobacterial counts: a randomised double-blind study in healthy humans. Eur J Clin Nutr 58: 462-466.

19. Malinen E, Matto J, Salmitie M, Alander M, Saarela M, et al. (2002) PCRELISA-II: analysis of Bifidobacterium populations in human faecal samples from a consumption trial with Bifidobacterium lactis $\mathrm{Bb}-12$ and a galactooligosaccharide preparation. Syst Appl Microbiol 25: 249-258.

20. Jaskari J, Kontula P, Siitonen A, Jousimies-Somer H, Mattila- Sandholm T, et al. (1998) Oat beta-glucan and xylan hydrolysates as selective substrates for Bifidobacterium and Lactobacillus strains. Appl Microbiol Biotechnol 49: 175181

21. Macfarlane GT, Macfarlane S (1997) Human colonic microbiota: Ecology physiology and metabolic potential of intestinal bacteria. Scand J Gastroenterol Suppl 32: 3-9.

22. Macfarlane GT, Gibson GR (1994) Metabolic activities of the normal colonic flora In S A W Gibson Human health: The contribution of microorganisms, Springer, London.

23. O'Sullivan MG (1996) Metabolism of bifidogenic factors by gut flora - An overview. Bulletin of International Dairy Foundation 313: 23-25.

24. Cummings JH, Macfarlane GT (1991) The control and consequences of bacterial fermentation in the human colon. J Appl Bacteriol 70: 443-459.

25. Mussatto ST, Mancilha IM (2007) Non-digestible oligosaccharides: A review. Carbohydrate Polymers 68: 587-597.

26. Hui YH, Gorham JR, Murrell KD, Cliver DO (1994) Food borne diseases handbook - Diseases caused by bacteria New York: Marcel Dekker Inc, New York.

27. Bengmark S (2005) Bioecologic control of the gastrointestinal tract: the role of flora and supplemented probiotics and synbiotics. Gastroenterol Clin North Am 34: 413-436.

28. Lim CC, Ferguson LR, Tannock GW (2005) Dietary fibres as "prebiotics": implications for colorectal cancer. Mol Nutr Food Res 49: 609-619.

29. Kanauchi O, Nakamura T, Agata K, Mitsuyama K, Iwanaga T (1998) Effects of germinated barley foodstuff on Dextran sulfate Sodium-Induced colitis in rats. J Gastroenterol 33: 179-188.

30. Fukuda M, Kanauchi O, Araki Y, Andoh A, Mitsuyama K, et al. (2002) Prebiotic treatment of experimental colitis with germinated barley foodstuff: a comparison with probiotic or antibiotic treatment. Int J Mol Med 9: 65-70.

31. Hoentjen F, Welling GW, Harmsen HJ, Zhang X, Snart J, et al. (2005) Reduction of colitis by prebiotics in HLA-B27 transgenic rats is associated with microflora changes and immunomodulation. Inflamm Bowel Dis 11: 977-985.

32. Rumi G, Tsubouchi R, Okayama M, Kato S, Mozsik G, et al. (2004) Protective effect of lactulose on dextran sulfate sodium-induced colonic inflammation in rats. Dig Dis Sci 49: 1466-1472.

33. Lara-Villoslada F, Debras E, Nieto A, Concha A, Galvez J, et al. (2006) Oligosaccharides isolated from goat milk reduce intestinal inflammation in a rat model of dextran sodium sulfate-induced colitis. Clinical Nutr 25: 477-488.

34. Kleessen B, Hartmann L, Blaut M (2001) Oligofructose and long-chain inulin influence on the gut microbial ecology of rats associated with a human faecal flora. Br J Nutr 86: 291-300.
35. Oudenhoven B, Bruggencate SJT, Wissink ML, van der Meer R (2003) Dietary fructo-oligosaccharides and lactulose inhibit intestinal colonisation but stimulate translocation of Salmonella in rats. Gut 52: 1572-1578.

36. Campbell JM, Fahey Jr GC, Wolf BW (1997) Selected indigestible oligosaccharides affect large bowel mass cecal and fecal short-chain fatty acids $\mathrm{pH}$ and microflora in rats. J Nutr 127: 130-136.

37. Lewis S, Brazier J, Beard D, Nazem N, Proctor D (2005) Effects of metronidazole and oligofructose on faecal concentrations of sulphatereducing bacteria and their activity in human volunteers Scandinavian. J Gastroenterol 40: 1296-1303.

38. Bruggencate SJT, Bovee-Oudenhoven IM, Lettink-Wissink ML, Vander Meer R (2005) Dietary fructooligosaccharides increase intestinal permeability in rats. $J$ Nutr 135: 837-842.

39. Cherbut C, Michel C Lecannu G (2003) The prebiotic characteristics of fructooligosaccharides are necessary for reduction of TNBS-induced colitis in rats. J Nutr 133: 21-27

40. Moreau NM, Martin LJ, Toquet CS, Laboisse CL, Nguyen PG, et al. (2003) Restoration of the integrity of rat caeco-colonic mucosa by resistant starch but not by fructo-oligosaccharides in dextran sulfate sodium-induced experimental colitis. British J Nutr 90: 75-85.

41. Ito M, Deuguchi Y, Miyamori A, Matsumote K, Kikuchi H, et al. (1990) Effects of administration of galactooligosaccharides on the human faecal microflora stool weigh and abdominal sensation. Microbial Ecology Health Diseases 3 : 285-292.

42. McBain AJ, Macfarlane GT (2001) Modulation of genotoxic enzyme activities by non-digestible oligosaccharide metabolism inin-vitro human gut bacterial ecosystems. J Medical Microbiol 50: 833-842.

43. Burns AJ, Rowland I (2000) Anti-carcinogenicity of probiotics and prebiotics Curr Issues Intest Microbiol 1: 13-24.

44. Silvi S, Rumney CJ, Cresci A, Rowland IR (1999) Resistant starch modifies gut microflora and microbial metabolism in human flora-associated rats inoculated with feces from Italian and UK donors. J Applied Microbiol 86: 521-530.

45. Topping DL, Clifton PM (2001) Short chain fatty acids and human colonic function: roles of resistant starch and nonstarch polysaccharides. Physiol Rev 81: 1031-1064.

46. Weng M, Walker W (2006) Bacterial colonization probiotics and clinical disease. J Paediatric 149: 107-114.

47. Neaville WA, Tisler C, Bhattacharya A (2003) Developmental cytokine response profiles and the clinical and immunologic expression of atopy during the first year of life. J Allergy Clin Immunol 112: 740-746.

48. Osborn DA, Sinn JK (2007) Prebiotics in infants for prevention of allergic disease and food hypersensitivity. Cochrane Database Systematic Reviews. 4: 64-74.

49. Arslanoglu S, Moro GE, Schmitt J, Tandoi L, Rizzardi S, et al. (2008) Early dietary intervention with a mixture of prebiotic oligosaccharides reduces the incidence of allergic manifestations and infections during the first two years of life. J. of Nutr. 138: 1091-1095.

50. Van der Aa LB, Heymans HS, Van Aalderen WM, Sprikkelman AB (2010) Probiotics and prebiotics in atopic dermatitis: review of the theoretical background and clinical evidence. Paediatric Allergy Immunology 21: 355-367.

51. Abrams SA, Griffin IJ, Hawthorne KM, Liang L, Gunn SK, et al. (2005) A combination of prebiotic short- and long-chain inulin-type fructans enhances calcium absorption and bone mineralization in young adolescents. Am J Clinical Nutr 82: 471-476.

52. Wong ND, Cupples LA, Ostfeld AM, Levy D, Kannel WB (1989) Risk factors for long-term coronary prognosis after initial myocardial infarction: the Framingham Study. Am J Epidemiol 130: 469-480.

53. Singh RB, Rastogi SS, Verma R, Laxmi B, Singh R, et al. (1992) Randomised controlled trial of cardioprotective diet in patients with recent acute myocardia infarction: results of one year follow up. British Medical J 304: 1015-1019.

54. Fiordaliso M, Kok N, Desager JP, Goethals F, Deboyser D, et al. (1995) Dietary oligofructose lowers triglycerides phospholipids and cholesterol in serum and very low density lipoproteins of rats. Lipids 30: 163-167.

55. Rault-Nania MH, Gueux E, Demougeot C, Demigne C, Rock E, et al. (2006) Inulin attenuates atherosclerosis in apolipoprotein $\mathrm{E}$-deficient mice. British $\mathrm{J}$ of Nutr 96: 840-844. 
Citation: Younis K, Ahmad S, Jahan K (2015) Health Benefits and Application of Prebiotics in Foods. J Food Process Technol 6: 433. doi: 10.4172/2157-7110.1000433

56. Van Dokkum W, Wexendonk B, Srikumar TS, Van Den Heuval EG (1999) Effect of nondigestible oligosaccharides on large bowel functions blood lipid concentrations and glucose absorption in young healthy male subjects. European J Clinical Nutr 53: 1-7.

57. Alles MS, De Roos NM, Bakx JC, Van De Lisdonk E, Zock PL, et al. (1999) Consumption of fructooligosaccharides does not favorably affect blood glucose and serum lipid concentrations in patients with type 2 diabetes. Am Clinical Nutr 69: 64-69.

58. Jackson KG, Taylor GR, Clohessy AM, Williams CM (1999) The effect of the daily intake of inulin on fasting lipid insulin and glucose concentrations in middle-aged men and women. British J Nutr 82: 23-30.

59. Davidson MH, Synecki C, Maki KC, Drennen KB (1998) Effects of dietary inulin in serum lipids in men and women with hypercholesterolaemia. Nutral Research 3: 503-517.

60. Causey JL, Feirtag JM, Gallaher DD, Tungland BC, Slavin JL (2000) Effects of dietary inulin on serum lipids blood glucose and the gastrointestinal environment in hypercholesterolaemic men. Nutral Research 20: 191-201.

61. Brighenti F, Casiraghi MC, Canzi E, Ferrari A (1999) Effect of consumption of a ready-to-eat breakfast cereal containing inulin on the intestinal milieu and blood lipids on healthy male volunteers. European of Clinical Nutr 53: 726-733.

62. Chow JM (2002) Probiotics and prebiotics: A brief overview. J Renal Nutr 12: 76-86.

63. Huebner J, Wehling RL, Hutkins RW (2007) Functional activity of commercial prebiotics. International Dairy 17: 770-775.

64. Huebner J, Wehling RL, Parkhurst A, Hutkins RW (2008) Effect of processing conditions on the prebiotics activity of commercial prebiotics. International Dairy 18: 287-293.

65. Bohm A, Kaiser I, Trebstein A, Henle T (2005) Heat-induced degradation of inulin. European Food Research and Technology 220: 466-471.

66. Bohm A, Kleessen B, Henle T (2006) Effect of dry heated inulin on selected intestinal bacteria. European Food Research and Technology 222: 737-740.

67. L'Homme C, Arbelot M, Puigserver A, Biagini A (2003) Kinetics of hydrolysis of fructooligosaccharides in mineral-buffered aqueous solutions: Influence of $\mathrm{Ph}$ and temperature. J Agric Food Chem 51: 224-228.

68. Crittenden RG, Playne MJ (1996) Production properties and applications of food-grade oligosaccharides. Trends in Food Science Technology 7: 353-361.

69. Moshfegh AJ, Friday JE, Goldman JP, Ahuja JKC (1999) Presence of inulin and oligofructose in the diets of Americans. J Nutr 129: 1407-1411.

70. Franck A (2002) Technological functionality of inulin and oligofructose. British of Nutr 87: 287-291.

71. Nelson AL (2002) High-fibre ingredients Minnesota: Eagan Press.

72. Sghir A, Chow JM, Mackie RI (1998) Continuous culture selection of bifidobacteria and lactobacilli from human faecal samples using fructooligosaccharide as selective substrate. Applied Microbiology 85: 769-777.

73. Schaafsma G (2008) Lactose and lactose derivatives as bioactive ingredients in human. Nutr. International Dairy 18: 458-465.

74. Boehm G, Stahl B (2007) Oligosaccharides from milk of Nutr. 137: 847-849.

75. Donovan S (2006) Role of human milk components in gastrointestinal development: current knowledge and future needs. J Paediatrics 149: 49-61.

76. Brussels (2003) European Commission Scientific Committee on Food Report of the Scientific Committee on Food on the Revision of Essential Requirements of Infant Formulae and on Formulae Brussels Belgium: European Commission, Belgium.

77. Arslanoglu S, Moro GE, Boehm G (2007) Early supplementation of prebiotic oligosaccharides protects formula-fed infants against infections during the first 6 months of life. J Nutr 137: 2420-2424.

78. Boehm G, Lidestri M, Casetta P (2002) Supplementation of a bovine milk formula with an oligosaccharide mixture increases counts of faecal bifidobacteria in preterm infants. Arch Dis Child Fetal Neonatal Ed 86: 178-181.

79. Moro G, Minoli I, Mosca M (2002) Dosagerelated bifidogenic effects of galacto- and fructooligosaccharides in formula-fed term infants. J Pediatric Gastroenterol Nutr 34: 291-295.
80. Schmelzle H, Wirth S, Skopnik H (2003) Randomized double-blind study of the Neutral efficiency and bifidogenicity of a new infant formula containing partially hydrolyzed protein a high beta-palmitic acid level and non-digestible oligosaccharides. J Pediatric Gastroenterol Nutr 36: 343-351.

81. Bettler J, Euler R (2006) An evaluation of the growth of term infants fed formula supplemented with fructo-oligosaccharides. International J Probiotics 1: 19-26.

82. Scholtens PA, Alles MS, Bindels JG, van der Linde EG, Tolboom JJ, et al. (2006) Bifidogenic effects of solid weaning foods with added prebiotic oligosaccharides: a randomised controlled clinical trial. J Pediatric Gastroenterol Nutr 42: 553-559.

83. Cardarelli HR, Saad SMI, Gibson GR, Vulevic J (2007) Functional petit-suisse cheese: Measure of the prebiotic effect. Food microbiology 13: 200-207.

84. Rodrigues D, Rocha-Santos TAP, Gomes AM, Goodfellow BJ, Freitas AC (2012) Lipolysis in probiotic and synbiotic cheese: The influence of probiotic bacteria prebiotic compounds and ripening time on free fatty acid profiles. Food Chemistry 131: 1414-1421

85. Debon J, Prudencio ES, Petrus JCC (2010) Rheological and physico-chemical characterization of prebiotic microfiltered fermented milk. J Food Engineering 99: 128-135.

86. Debon J, Prudencio ES, Petrus JCC, Fritzen-Freire CB, Muller CMO, et al. (2012) Storage stability of prebiotic fermented milk obtained from permeate resulting of the microfiltration process. Food Science and Technology 47: 96-102.

87. Cruz AG, Cavalcanti RN, Guerreiro LMR, Sant'Ana AS, Nogueira LC, et al (2013) Developing a prebiotic yogurt: Rheological physico-chemical and microbiological aspects and adequacy of survival analysis methodology of Food Engineering 114: 323-330.

88. Guergoletto KB, Magnani M, Martin JS, Andrade CGTJ, Garcia S (2010) Survival of Lactobacillus casei (LC-1) adhered to prebiotic vegetal fibers. Innovative Food Science and Emerging Technologies 11: 415-421.

89. Damen B, Pollet A, Dornez E, Broekaert WF, Haesendonck IV, et al. (2012) Xylanase mediated in situ production of arabinoxylan oligosaccharides with prebiotic potential in whole meal breads and breads enriched with arabinoxylan rich materials. Food Chemistry 131: 111-118.

90. Morais EC, Cruz AG, Faria JAF, Bolini HMA (2014) Prebiotic gluten-free bread Sensory profiling and drivers of liking. Food Science and Technology 55: 248254.

91. Tuohy KM, Kolida S, Lustenberger AM, Gibson GR (2001) The prebiotic effects of biscuits containing partially hydrolysed guar gum and fructooligosaccharides - a human volunteer study.

92. Mantzouridou F, Karousioti A, Kiosseoglou V (2013) Formulation optimization of a potentially prebiotic low-in-oil oat-based salad dressing to improve Lactobacillus paracasei subsp paracasei survival and physicochemical characteristics. Food Science and Technology 53: 560-568.

93. Huezo MER, Duran-Lugo R, Prado-Barragan LA, Cruz-Sosa F, Lobato-Calleros C, et al. (2007) Pre-selection of protective colloids for enhanced viability of Bifidobacterium bifidum following spray-drying and storage and evaluation of aguamiel as thermoprotective prebiotic. Food Research International. 40: 1299-1306.

94. Soukoulis C, Behboudi-Jobbehdar S, Yonekura L Parmenter C, Fisk I (2014) Stability of lactobacillus rhamnosus gg in prebiotic edible films. Food Chemistry 308-8146.

95. Tarrega A, Rocafull A, Costell E (2010) Effect of blends of short and long-chain inulin on the rheological and sensory properties of prebiotic low-fat custards. Food Science and Technology 43: 556-562.

96. Tarrega A, Torres JD, Costell E (2011) Influence of the chain-length distribution of inulin on the rheology and microstructure of prebiotic dairy desserts. J Food Engineering 104: 356-363. 